2014-01-02

\title{
Impact of rural infrastructure on farm and non-farm enterprise choice and income in Bangladesh
}

\section{Rahman, Sanzidur}

http://hdl.handle.net/10026.1/3999

\subsection{3/jda.2014.0006}

Journal of Developing Areas

Tennessee State University College of Business

All content in PEARL is protected by copyright law. Author manuscripts are made available in accordance with publisher policies. Please cite only the published version using the details provided on the item record or document. In the absence of an open licence (e.g. Creative Commons), permissions for further reuse of content should be sought from the publisher or author. 


\title{
Impact of rural infrastructure on farm and non-farm enterprise choice and income in
}

\section{Bangladesh}

\section{Sanzidur Rahman}

\begin{abstract}
Impact of rural infrastructure on economic development is indirect and complex. The present study jointly determines the impact of rural infrastructure on the decision to choose between farm and non-farm enterprises vis-à-vis income by Bangladeshi rural households (4,195 households from 139 villages) using a bivariate Tobit model. The model diagnostic reveals that the decision to choose enterprises is significantly correlated, justifying use of a bivariate approach. Rural infrastructure has a significant but opposite impact on enterprise choices vis-à-vis income. Other major determinants with varying level of influences are farm size, livestock resources, education, farming experience and household assets. However, femaleheaded households are doubly disadvantaged as they have failed to participate in both enterprises and consequently earned significantly less. Policy implications include investment in rural infrastructure, irrigation, rural electrification, education, livestock resources, tenurial reforms, as well as targeted approach to promote welfare of the female-headed households, e.g., creation of a hired labor market for females.
\end{abstract}

JEL Classification: H54; D13; D22

Key Words: Rural infrastructure, enterprise choice, farm and non-farm income, bivariate Tobit model, Bangladesh.

\section{Introduction}

Infrastructure, in the development literature, generally refers to the services and facilities that are an integral part of human life. Infrastructure includes facilities for transportation, communication, power, water suppy, education, health care, irrigation, drainage, as well as all other types of public utilities. The role of infrastructure in economic development is 
complex and its effects are indirect. The crucial role of infrastructure in augmenting agricultural productivity has been recognised only from the mid-1980s, spurred by the observation of widespread stagnancy and sluggish growth in the sector (Ahmed and Donovan, 1989). This has lead to a series of research studies aimed at establishing the case for investment in rural infrastructure to enhance agricultural productivity (e.g., Evenson, 1986; Mann, 1988; Ahmed and Hossain, 1990, Fan et al., 2000; Renkow et al., 2001; Khandker et al., 2006). In fact, investments in rural infrastructure (e.g., roads and rural electrification) were seen as the means to change the behavior of farmers (Evenson, 1986). Ahmed and Hossain (1990) as well as Renkow et al., (2001) concluded that rural infrastructure drastically reduces the marketing cost of agricultural products, thereby exerting a far reaching impact on improving the comparative advantage of a country to compete in the world market. Ahmed and Hossain (1990) further noted that infrastructure is critical in the diffusion of modern agricultural technology, as easy access to transportation and communication system could promote extension activities, the marketing of products, and the purchase of modern inputs. Similarly, Mann (1988), drawing on experience from Pakistan, suggested that a realistic strategy to promote agricultural growth should be to repair massive rural infrastructure supporitng the agricultural system. Fan et al., (2000) noted the significant poverty reducing impacts of public infrastructure investment in India, which was echoed by Khandker et al., (2006) for Bangladesh, particularly, investments in the rural road infrastructure. Similarly, Hanjra et al., (2009) advocated investment in agricultural water management and complementary rural infrastructure to break the poverty trap for African smallholder farming communities. Rahman (2009) and Asadullah and Rahman (2009) noted the significant positive impact of rural infrastructure investment in improving technical efficiency of crop production in Bangladesh. However, in contrast, results from Segun et al., 
(2008) showed that rural infrastructure development had a significant negative influence on farm productivity in Nigeria ${ }^{1}$.

Only recently, the thrust of the research studies has moved on to examine the impact of rural infrastructure on non-farm sector of the rural economy as well. However, the results obtained there are somewhat mixed. For example, Fan and Zhang (2004), using a conventional growth accounting approach, concluded that rural infrastructure and education played prominent roles in explaining rural non-farm productivity differences in China. Gibson and Olivia (2010) also claimed that the quality of two key types of infrastructure roads and electricity - affect both employment and income from non-farm enterprise in Indonesia and, therefore, recommended further investment. Barrios (2008) noted that rural roads generated the largest impact on the index of rural development and income growth in the Philippines. However, interestingly, Nkonya et al., (2008) concluded that infrastructure investments though demonstrating positive short-term impacts on the access to markets and transportation costs, showed no visible impacts on non-farm activities in Nigeria.

As mentioned earlier, since the role of infrastructure in development is indirect and complex, the methodology to examine its impact, particularly in cross-sectional studies, is also complex. Although there is sufficient evidence that infrastructure plays a significant role in various aspects of the rural economy (mentioned above), most of these studies have analyzed the impact of infrastructure by concentrating either on the farm sector or the nonfarm sector separately, as if the decision to participate in these sectors is independent of the other. This assumption ignores the fact that the rural households undertake a portfolio of

\footnotetext{
${ }^{1}$ Although the infrastructure index constructed by Segun et al., (2008) is identical to the index used in this study, their interpretation of its impact was incorrect. The negative sign on the coefficient of this composite index of underdevelopment of infrastructure implies positive influence on the dependent variable and viceversa.
} 
enterprises, and hence, derive income jointly from a range of sources rather than independently from one source, and therefore, may provide biased outcomes. For example, the types of enterprises chosen by the sampled households of this study include farming (mainly rice production but also other cereal and non-cereal crops) combined with either small businesses (e.g., rice trading, grocery shops, etc.) or self-employment (e.g., rickshawpulling, boat rowing, fishing, tailoring, etc.) or salaried employment (e.g., shop-keeping, working in garments industries, clerical jobs in public agencies, etc.) or livestock rearing (e.g., poultry and/or goat rearing).

Given this backdrop, the principal aim of the present study is to incorporate such dynamism in the household decision making process in the analysis of the impacts of rural infrastructure. In other words, we have examined the impact of rural infrastructure on the household's enterprise choice (i.e., farm and non-farm enterprise) while acknowledging the fact that the households may participate in either of the enterprises or both at the same time, and hence derive incomes from their choices depending on their intensity of participation in each enterprise. This requirement has led us to adopt a bivariate modelling approach, specifically the bivariate Tobit model, which is not commonly seen in the relevant literature. We do so by using a large dataset of 4,195 households from 139 villages in the Matlab upazila (sub-district, refers to government administrative unit) of Bangladesh. The other advantage of this bivariate approach, as opposed to the univariate approach commonly seen in the literature (e.g., single equation Tobit models of household's engaged in farm enterprise or non-farm enterprise estimated separately), is that it is more efficient. This is because this approach not only nests individual univariate models but also enables us to determine the jointness of the decision making process by providing an estimate of the correlation between the error terms of the two univariate models. 
The paper proceeds as follows; section 2 provides an overview of the infrastructural improvements in Bangladesh as well as the relative importance of the farm and non-farm sectors in generating employment and income in the economy; section 3 describes the analytical framework and the data; section 4 presents the results; and finally section 5 concludes and draws policy implications.

\section{State of infrastructure development in Bangladesh}

Bangladesh inherited a rudimentary state of infrastructure from its past when it was a part of Pakistan. The country later emerged as an independent nation on December 16, 1971 with serious damage to its already fragile and rudimentary infrastructure during the nine months of liberation war. Nevertheless, soon after independence, the government of Bangladesh placed a major policy thrust on improving road infrastructure, rural electrification and irrigation in order to facilitate diffusion of the Green Revolution technology to attain the ambitious goal of self-sufficiency in foodgrain production. This is because, historically, Bangladesh has been a food deficit country with $10 \%$ of its domestic demand for food met by imports and/or food aid (Hossain, 1989).

Table 1 presents the trends in the state of infrastructure development in Bangladesh, covering the period 1982-2005. Road construction, particularly the 'high type' road (i.e., permanent in nature and paved with asphalt or concrete) showed an impressive average annual growth rate of $5 \%$. On the other hand, 'low type' road (i.e., temporary earthen or brick-laden roads with narrow width) grew at an annual rate of only $2 \%$ during the same period. It should be noted that these road infrastructures were and are constructed and maintained by the National Highways Department. The other type of roads, i.e., the local feeder roads, were and are constructed and maintained by the Local Government Engineering Departments (LGED), and information on these road infrastructures is not publicly available. However, a recent World Bank estimate showed that the length of such rural roads which 
connect villages with local government centres and the national highways is about 78,495 $\mathrm{kms}(\mathrm{WB}, 2010)$. Also, a further 171,335 kms of village roads connect villages with the local markets, union headquarters, farms, etc. (WB, 2010).

Rural electrification, i.e., the provision of electricity to village households, although initiated in 1981, has recorded a dramatic rise only from the mid-1990s. Overall, the growth rate was an impressive $10 \%$ per annum (Table 1). However, it should be noted that although $67 \%$ of the approximate total of 68,000 villages were connected with electricity by 2005 , the actual hours of continuous electricity supply per day (i.e., for the 24 hour period) is highly variable and uncertain. A similar situation is mirrored in the cities including nation's capital Dhaka.

The rate of growth in irrigated area, a key element in the diffusion of the Green Revolution technology package, is also impressive. The irrigated area grew at an annual rate of 5\% during 1982-2005 (Table 1). The main crop which uses irrigation is Boro rice (drywinter season), which has a high level of productivity and has been a main contributor to attaining the goal self-sufficiency in food grain production in Bangladesh in recent years.

It is clear from the above discussion that the rate of key infrastructural development in Bangladesh has been quite impressive. However, when the distribution of the employment of the labour force by major industries is considered, we see that there is only a $9 \%$ shift in employment from the broad agricultural to the non-agricultural sector over a 20 year period (1985-2005). At present, 48\% of the employment is still generated by the agricultural sector and the remaining $52 \%$ is generated by the manufacturing and services sector, implying that both of these sectors play almost an equal role in the Bangladesh economy in generating employment opportunities for the growing labour force. It should be noted that the scenario presented is an overview at the national level which is bound to have regional disparities in these indicators of infrastructural development as well as employment distribution, which is 
beyond the scope of this study.

\section{Methodology}

\subsection{Modelling the determinants of enterprise choice and its income: the bivariate Tobit}

\section{model}

In this study we examine two research questions: (a) whether infrastructure affects a household's decision to participate in a particular enterprise (while controlling for other socio-economic factors); and (b) what is the marginal effect of rural infrastructure on income (a reflection of the intensity of participation) derived from the chosen enterprise? In addressing these two research questions we explicitly allow for the possibility of households deciding to participate in either or both types of enterprises (farm and non-farm enterprises) at the same time.

A common approach to analyzing the determinants of any technological innovation and/or enterprise choice is to apply univariate Probit or Tobit regressions with variables representing the socio-economic circumstances of the households (e.g., Hossain, 1989; Shiyani, et al., 2002; Floyd et al., 2003; Ransom, et al., 2003) as well as indicators of infrastructure (e.g., Ahmed and Hossain, 1990; Nkonya et al., 2008; Gibson and Olivia, 2010). The implicit theoretical underpinning of such modelling is the assumption of utility maximization by rational producers and/or entrepreneurs, which is described below.

We postulate that households follow sequential decisions: first, whether to participate in a particular enterprise or not; and second, conditional on participation, what is the level or intensity of participation. In such a case, a censored regression model (i.e., Tobit model) is most suitable because it uses all observations, both those which are at the limit, usually zero (e.g., non-participants), and those above the limit (e.g., participants), to estimate a regression line as opposed to other techniques that use observations which are only above the limit value 
(McDonald and Moffit, 1980). The procedure also captures the latent level of intensity of potential households who decide not to participate in a particular enterprise.

The outcome function for participation in a particular enterprise (measured as net income derived from the chosen enterprise) is given by:

$Y_{i}^{*}=\gamma^{\prime} X_{i}+\mu_{i}$

where $X_{i}$ is the vector of regressors, $\gamma$ is the vector of parameters to be estimated, and $\mu_{i}$ is the error term. For households participating in the farm enterprise, $Y_{i}^{*}$ equals the actual level of income $\left(Y_{i}\right)$. For those who are not participating in the farm enterprise, $Y_{i}^{*}$ is an index reflecting potential income such that:

$$
\begin{aligned}
Y_{i} & =Y_{i}^{*} & & \text { if } \gamma^{\prime} X_{i}+\mu_{i}>0 \\
& =0 & & \text { if } \gamma^{\prime} X_{i}+\mu_{i}<0
\end{aligned}
$$

The advantage of the Tobit model as in Eq (2) is that it captures the decision to participate as well as the resulting outcome, whereas a probit model will provide information on the decision to participate only. Since we have observed that a substantial proportion of households participated in both farm and non-farm enterprises at the same time (Table 2), we postulate a bivariate Tobit model in order to capture this phenomenon of joint outcome:

$Y_{1 i}^{*}=\gamma^{\prime} X_{1 i}+\mu_{1 i}$

$Y_{1 i}=\operatorname{Maximum}\left(Y_{1 i}^{*}, 0\right)$ (the usual Tobit specification as in 2)

$Y_{2 i}^{*}=\gamma^{\prime} X_{2 i}+\mu_{2 i}$

$Y_{2 i}=\operatorname{Maximum}\left(Y_{2 i}^{*}, 0\right)$ (the usual Tobit specification as in 2)

$\mu_{i i}, \mu_{2 i} \approx N\left[0,0, \sigma_{1}^{2}, \sigma_{2}^{2}, \rho\right]$, cov ariance is $\sigma_{12}=\rho \sigma_{i} \sigma_{2}$

where $Y_{1 i}^{*}$ denotes income of the $i$ th household who has participated in the farm enterprise, and $Y_{2 i}^{*}$ denotes income of the $i$ th household who has participated in the non-farm enterprise, $\rho$ is the correlation between the error terms $\mu_{1 i}$ and $\mu_{2 i}$. The distributions are independent if 
and only if $\rho=0$. The full maximum likelihood estimation procedure is utilized using the NLOGIT-4 (ESI, 2007) software program to estimate the bivariate Tobit model.

\subsection{Data}

Data for this study comes from the Matlab Health and Socio-economic Survey (MHSS). The survey was conducted in all villages of the Matlab upazila (sub-district) in the year 1996. The dataset provides a rich description of the agricultural and non-agricultural profiles of the sample households and their asset portfolio, complete information on personal characteristics of the householders, as well as detailed information on infrastructural facilities in the study villages. The sample households were selected in two stages. First, a random sample of 2,678 residential neighbourhoods - baris - was selected from the entire Matlab upazila. Second, households were sampled. If a bari had just one household, it was always selected. In case of multi-household baris, two households were selected at random from each of the sample baris. This led to a total sample of 4,368 households ${ }^{2}$. After purging this sample of potential outliers and/or missing essential information, the final sample contains a total of 4,195 households located in 139 villages (originally 141 villages in total).

\subsection{Construction of the infrastructure index}

As mentioned earlier, the focus of this study is to measure the impact of rural infrastructure on the household economy in rural areas. As such, the urban and first-order infrastructures such as national highway, ports, airports, etc. were excluded. Ahmed and Donovan (1989) demonstrated that there is a gap in the methods of empirical measurement of the effects of infrastructure. Ahmed and Hossain (1990) developed a composite measure of infrastructure development as an index by applying a 'cost-of-access' approach, which was later adapted with some modification by Segun et al., (2007), Rahman (2009) and Asadullah and Rahman (2009). The index approach is suitable because such a measure reduces a large amount of

\footnotetext{
${ }^{2}$ Further details on the MHSS are available in Rahman et al. (2001).
} 
data to a single measure and incorporates both qualitative and quantitative aspects in its construction. However, a key element is the justification for inclusion of the types of infrastructure to construct this composite index.

The following eight elements of infrastructure were utilised to construct the composite index of rural infrastructure. These are: primary markets, secondary markets and/or growth centres, post offices, telephone offices, upazila headquarters, bus stops, boat stations, and banks. The justification for including these eight elements of infrastructure is that these indicators taken together encompass market infrastructure, key administrative and financial institutions and transport facilities. Data includes the existence of each of these facilities within the village, average distance to reach the facilities, travel cost incurred to reach these facilities and finally time taken to reach these facilities (see Table 2 for details).

The construction of the cost-based infrastructure index, adapted from Ahmed and Hossain (1990), is as follows. First, an individual cost of access to each facility $\left(I C_{i}\right)$ was computed. Second, the total cost (TC) of access was computed by summing up the individual costs $\left(I C_{i}\right)$ of access. Third, the $T C$ was correlated with the costs for each element $\left(I C_{i}\right)$ which then provided the correlation coefficients $\left(W_{i}\right)$ to be used as weights. Finally, the index of underdevelopment of infrastructure was constructed as a weighted average of the total cost. The formulation is:

$$
\begin{aligned}
I C_{i} & =\text { distance } x \text { cost per } \mathrm{km} \text { to element } i \\
T C & =\sum_{i} I C_{i} \\
W_{i} & =\text { correlation of } I C_{i} \text { with } T C, \text { and } \\
I N F & =\sum_{i}\left(W_{i} x I C_{i}\right) / \sum_{i} W_{i}
\end{aligned}
$$

In this formulation, a high index value implies underdeveloped infrastructure because either higher cost or longer distance is responsible for high index value. 
In order to assess the representativeness of this cost-based infrastructure index, a rotated factor analysis was applied to the infrastructure variables. The first factor incorporating bus station, upazila headquarters, and telephone offices explained about $94.5 \%$ of the total variation. The rank correlation among the two sets of weights, the communality from the factor analysis and the correlation coefficients (of $I C_{i}$ with $T C$ ) is 0.81 and is significant at $1 \%$ level $(p<0.01)$. This indicates that the index constructed using the cost-of-access approach represents satisfactorily the index constructed using the factor analytic approach. However, we have decided to use the cost-based infrastructure index in subsequent analyses. It should be noted that this is a village level index and, therefore, households from a single village will have the same index value as applied by Ahmed and Hossain (1990); Segun et al., (2008); Rahman (2009); and Asadullah and Rahman (2009).

\subsection{The empirical model}

A bivariate Tobit model is developed to empirically investigate the impact of rural infrastructure on the choice of farm and/or non-farm enterprises while controlling for other socio-economic factors underlying the decision to participate in these enterprises. The choice of the variables representing the socio-economic circumstances of the households as controls is based on the existing literature dealing with the impacts of rural infrastructure with similar justifications thereof (e.g., Ahmed and Hossain, 1990; Khandker et al., 2006; Segun et al., 2008; Nkonya et al., 2008; Rahman, 2009; Asadullah and Rahman, 2009; Gibson and Olivia, 2010). The socio-economic variables at the household level included in the model are: female headed households, main occupation of the household head, experience of the household head (proxied by age), level of education of the household head, maximum level of education in the household, household assets, farm operation size and livestock resources.

The four infrastructure variables at the village level included in the model are: a composite index of underdevelopment of infrastructure, electricity connection, irrigation 
facilities, and proximity to regional headquarters, i.e., Comilla district. The justification of including electricity and irrigation infrastructure is that these two indicators are critically important with regard to access, use and adoption of technologies. Also, such information is recorded and presented at the national level (Table 1). Proximity to regional headquarters is included in order to judge whether remoteness from a city location has any independent influence on enterprise choice vis-à-vis income.

We have added additional aspects of non-linearity in our model specification by adding squared terms of the selected variables. The squared term of any variable has its own interpretation, and denotes the rate of change of its influence on the probability to participate by the households in a particular enterprise.

\section{4. $\quad$ Results}

\subsection{Rural infrastructural facilities in the study villages}

Table 2 presents data on various types of infrastructural facilities in the study villages. It is interesting to see that there are a higher proportion of secondary markets than local markets in these study villages. Only $13 \%$ of the villages have electricity connection, whereas a massive $95 \%$ of the villages have irrigation facilities. This is because the Matlab upazila (sub-district) is home to the Meghna-Dhonagoda Flood Control, Drainage and Irrigation project which provides surface irrigation via canals to a large number of villages, unlike in other regions where irrigation access is largely through extracting groundwater by using either deep tube wells or shallow tube wells.

When distance to each of the infrastructural facilities is considered, it seems that bus stops are located quite far away at an average distance of $5 \mathrm{~km}$ as compared with boat stations ( $1.7 \mathrm{~km}$ distance) because of the presence of two major rivers, the Meghna and the Dhonagoda in the area, thereby, facilitating travel using waterways rather than roads. The average distance to the upazila headquarters Matlab is $6.3 \mathrm{~km}$. 
However, looking at the quality of access to infrastructure (proxied by time to reach the facilities), it seems that most of the facilities can be accessed within an hour except busstops, the telephone office and upazila headquarters, which require an extra 15-30 minutes of travel time. The cost of access to most of the facilities is under Tk 3.00 (USD 0.06 in 1996 prices) except bus-stops, the telephone office and the upazila headquarters which costs at least twice as mcuh or more.

\subsection{Socio-economic characteristics of the households}

Table 3 presents summary statistics of the socio-economic characteristics of the households and the state of rural infrastructure in the study villages classified by the household's choice of enterprise. We see significant differences in all of the socio-economic variables, except the proportion of female-headed households and education of the household head between enterprise choice categories. Also, significant differences exist with respect to all infrastructural variables, except proximity to Comilla (the district headquarter) between the enterprise choice categories. Farm operation size, livestock resources, and household assets are significantly higher amongst households choosing farm enterprise. Also, $42 \%$ of the household heads who chose farm enterprise identified farming as their primary occupation. This finding is rather lower than expected. Also, it is surprising to see that these households are also endowed with significantly higher level of education.

With respect to the infrastructural variables, we see that the farm households are located in villages with underdeveloped infrastructure, with no electricity connection but with significantly higher access to irrigation facilities. The reverse is true for the households choosing non-farm enterprise. For example, non-farm incomes are higher amongst households choosing non-farm enterprise, as expected. Nevertheless, it is worth mentioning that in absolute terms, income derived from farm enterprise is significantly lower than the income derived from non-farm enterprise regardless of enterprise choice. Approximately, 
$19.2 \%$ of the sampled households are engaged in both farm and non-farm enterprise at the same time, thereby, justifying use of a bivariate approach in our analysis.

\subsection{Impact of rural infrastructure on enterprise choice vis-à-vis income}

The result of the full information maximum likelihood estimation of the bivariate Tobit model is presented in Table 4. Prior to the discussion of the findings, we present the results of the model diagnostic tests reported in the lower panel of Table 4 . Globally, $63.5 \%$ of the estimated coefficients were significantly different from zero at the $10 \%$ level, at least indicating that the inclusion of these variables was correctly justified in explaining the determinants of enterprise choice. The key hypothesis that the "correlation of the disturbance term between the two equations "income from the choice of farm enterprise" and "income from the choice of non-farm enterprise" is zero \{i.e., $\rho(F E, N F E)=0\}$ " is rejected at the $10 \%$ level of significance, implying that the use of a bivariate Tobit model to determine households' decision underlying choice of enterprise vis-à-vis income is correctly justified. This result also confirms that a univariate analysis of such decisions will lead to biased results, which is commonly seen in the literature. Also, both of the sigma values were significantly different from zero at the $1 \%$ level.

It is clear from Table 4 that a number of socio-economic factors as well as the state of infrastructure affect households' enterprise choice but work in opposite direction regarding decision to choose farm or non-farm enterprises, which cannot be determined a priori. A total of 11 variables have significant relationships with the decision to choose farm enterprise and another nine variables have significant relationships with the decision to choose non-farm enterprise. The likelihood of choosing farm enterprise vis-à-vis income is significantly higher for households whose heads identified farming as their primary occupation and are also endowed with high level of education, household assets, farm operation size and livestock resources. On the other hand, the decision to choose non-farm enterprise is significantly higher 
for households who are not primarily a farming household, have experience of farming but are less educated. This finding is in contrast to that of Gibson and Olivia (2010), who noted that in rural Indonesia, the secondary level of schooling of the household head has a significant influence $(\mathrm{p}<0.10)$ on non-farm earnings, whereas experience has no influence. The most striking feature of our results is that the female-headed households are doubly disadvantaged as they have failed to participate in either of the enterprises and hence earned significantly less. However, Gibson and Olivia (2010) did not find any influence of female-headed households on income derived from non-farm enterprises, implying that the cateogry of household head has no influence in rural Indonesia, which is at contrast to our results.

Coming to our key variable of interest, i.e., the impact of the state of infrastructure on enterprise choice, the current study reveals an interesting story. The likelihood of the households' choice of farm enterprise vis-à-vis income is significantly higher in villages with underdeveloped infrastructure ${ }^{3}$, also with no electricity connection, but which have access to irrigation facilities and are located closer to the regional headquarters, Comilla. The scenario is exactly opposite for the households choosing non-farm enterprises. The decision of the households to choose non-farm enterprises vis-à-vis income is significantly higher in villages with developed infrastructure, which also have electricity connection, but no irrigation facilities. The overall implication is that the choice of farm enterprise largely depends on the existence of irrigation facilities and proximity to a large market (i.e., Comilla), whereas, the choice of non-farm enterprise is dependent upon the existence of developed infrastructure and electricity connection. Ahmed and Hossain (1990) reported a significant influence of rural infrastructure on the income from fisheries and livestock resources as well as wage income but not on the income from business and industries, which is in contrast to our results. They also

\footnotetext{
${ }^{3}$ The constructed index is a measure of underdevelopment of rural infrastructure. Therefore, a negative sign on the coefficient implies positive influence on the dependent variable and vice-versa.
} 
concluded that irrigation is the major determinant of modern agricultural technology adoption, whereas the direct effect of infrastructure is insignificant, which however, matches our results. Gibson and Olivia (2010) noted that the non-farm earnings are significantly higher in villages that are close to the provincial capital, whereas we find such influence on the farm earnings instead. With respect to electricity connection, Gibson and Olivia (2010) noted that the villages with good electricity connection have a significantly positive influence on the non-farm earnings, consistent with our findings.

Although the coefficients on the variables in Table 4 can reveal the direction of influence, they cannot directly reveal their actual magnitude. Therefore, we have computed the marginal effects of the variables on the earnings from farm and non-farm enterprises and the results are presented in Table 5. It is clear from Table 5 that, apart from the marginal effects of the dummy variables (which measure only discrete changes), we see that the level of household education has the highest impact on the earning from farm enterprises, followed by livestock resources and farm size. The figures show that a one percent increase in the maximum level of education will raise farm earnings by $0.40 \%$, which is substantial. The corresponding figures for livestock and farm size increases are $0.13 \%$ and $0.08 \%$, respectively. The impact of household assets, although highly significant, is small. On the other hand, experience has the highest impact on deriving income from non-farm enterprises. A one percent increase in the years of experience will raise non-farm earning by almost one percent. However, the rate of increase in earnings in response to changes in experience will decline by $0.01 \%$.

The impact of rural infrastructure in deriving income from non-farm enterprises is also very high, and therefore, re-establishes the case for investment in various elements of rural infrastructure. A one percent improvement in the rural infrastructure index will raise non-farm earning by $0.22 \%$, which is substantial.

\section{$5 \quad$ Discussion and policy implications}


The study explores the impact of rural infrastructure on enterprise choice vis-à-vis income amongst Bangladeshi households using a bivariate Tobit model. The results are discussed explicitly in light of the existing literature, to compare and contrast our findings. In addition, although each country is unique in its setting and, therefore, should be studied separately, we expect to see a certain level of robustness in the results across studies. Our approach also allows for greater flexibility as it enables us to examine the household's decision to participate either in a farm or non-farm enterprise or both at the same time. The model diagnostics confirmed the jointness of the decision on enterprise choice, thereby, justifying our use of the bivariate modelling approach.

The results reveal that a number of socio-economic factors as well as the state of rural infrastructure affect households' enterprise choice decisions, but work in the opposite directions regarding participation in farm or non-farm enterprise. Resource rich and educated households with access to irrigation but located in villages with anunderdeveloped infrastructure are more likely to choose a farm enterprise. Proximity to the regional headquarter also influences farm enterprise choice vis-à-vis income. On the other hand, households' choice of non-farm enterprise is influenced by experienced households and villages with a developed rural infrastructure and electricity connection. The broader implication of this finding is that investment in the rural infrastructure goes a long way and exerts differential impacts on households' enterprise choice and earning derived from such choice. Furthermore, femaleheaded households loose out totally as they fail to participate in any of the enterprises and hence earn significantly less income. This is also evident from the fact that the average farm income of the female-headed households is estimated at Tk.1,800.5, which is significantly lower than the male-headed households earning Tk.5,368.7 $(\mathrm{p}<0.01)$. Similarly, average nonfarm income of the female-headed households is estimated at Tk.10,000.6, which again is significantly lower than the male-headed households earning Tk.23,064.9 $(\mathrm{p}<0.01)$. 
The policy implications of this study are clear. On one hand, the thrust of the measures to promote the choice of farm enterprise vis-à-vis income should be on investment targeted at the household level. These are: investment in education, livestock resources and tenurial reform. This is because education matters in raising productivity, boosting potential output and improving efficiency in Bangladesh (Asadullah and Rahman, 2009). Similarly, Rahman (2010a) noted that livestock resources and farm capital assets, which are also unequally distributed among the farming population, are essential in farming too and, therefore, should be promoted, which is consistent with our findings. However, conventional land reform policies to consolidate land will not be feasible in Bangladesh. This is because of the technical and economic limitations, as well as the political economy of its agrarian structure coupled with very low attainable farm size of 0.21 hectare per marginal/landless household after redistribution, which is unviable as a livelihood resource (Rahman and Rahman 2008). Therefore, the policy thrust should be to facilitate the operation of land rental markets via tenurial reform, so that the marginal/landless farm households can participate in the production process through renting-in land that provides a fair return for their labor and effort. In terms of infrastructural provision to promote farm enterprise choice and earning, the undisputed importance of irrigation facility as a precondition is clear. The average annual 5\% growth rate of irrigated area over the past three decades (Table 1) owing to governmental policy is a step in the right direction and should be accelerated further.

On the other hand, measures to promote non-farm enterprise choice and earning rests largely on investment in the rural infrastructure. It is clear that rural electrification and improvement in the eight elements of infrastructure (used to construct the index) are essential in influencing households' decision to choose non-farm enterprises. In this respect, the remarkable average annual $10 \%$ growth rate of rural electrification and $5 \%$ growth rate in road construction are steps in the right direction. It is imperative that all of the $68,000+$ 
villages of Bangladesh should be connected with electircity as soon as possible. Also, accessibility to all weather roads by the rural population must be improved. At present, only an estimated $39 \%$ of the rural population in Bangladesh has access to an all season road (WB, 2010). Gibson and Olivia (2010) also confirmed that the two key types of infrastructure roads and electricity - significantly improve both employment in and income from non-farm enterprises, hence reinforcing our policy implications. Our results also showed that experience at the household level play an important role in non-farm enterprise choice. Therefore, targeted skills training programs on non-farm enterprise at the household level may be an important option to equip young entrepreneurs in order to compensate for their lack of experience.

Furthermore, targeted intervention is needed for the female-headed households to enable them to participate in either or both types of enterprises. Rahman (2010b) advocated the creation of a hired labor market for females so that more women can be involved in the production process and contribute positively towards agricultural growth. This is because women laborers do contribute significantly to agricultural productivity and efficiency (Rahman, 2010b).

Realisation of all these policy measures, although formidable and challenging, will play a synergistic role in improving households' participation in both types of enterprises. Thus far, Bangladesh has only succeeded in shifting the employment of its growing labor force from the farm sector to non-farm sector by $9 \%$ over the past two decades (Table1). Currently, both sectors are contributing almost equally in terms of employment generation, but it is clear that the income generated from non-farm sources is substantially higher. For example, GDP per capita of Bangladesh is US\$1,501 in 2008 and the sectoral contribution to this GDP is $19.0 \%, 28.5 \%$, and $52.5 \%$ by agriculture, industries and services sectors, respectively (ADB, 2009). Our results clearly re-establish that the key to promote growth in 
the non-farm sector in Bangladesh lies in improving the rural infrastructure and rural electrification. 


\section{References}

ADB, 2009. Key Indicators for the Asia and Pacific, 2009. 40 ${ }^{\text {th }}$ Edition. Asian Development Bank, the Philippines.

Ahmed, R. and Donovan, C. 1992. Issues of infrastructural development: a synthesis of the literature. International Food Policy Research Institute, Washington, D.C.

Ahmed, R. and Hossain, M. 1990. Developmental impact of rural infrastructure in Bangladesh. IFPRI Research Report 83. International Food Policy Research Institute, Washington, D.C.

Asadullah, M.N., Rahman, S. 2009. "Farm productivity and efficiency in rural Bangladesh: the role of education revisited". Applied Economics, 41: 17-33.

Barrios, E.B. 2008. Infrastructure and rural development: households' perception on rural development. Progress in Planning, 70: 1-44.

BBS, (various issues). Statistical Yearbooks of Bangladesh. (Various Issues). Bangladesh Bureau of Statistics, Dhaka.

ESI, 2007. NLOGIT-4, Econometric Software, Inc. New York.

Evenson, R.E., 1986. Infrastructure, output supply and input demand in Philippine agriculture: provisional estimates. Journal of Philippine Development, 13: 62-76.

LFS, (various issues). Labour Force Survey of Bangladesh. Bangladesh Bureau of Statistics, Dhaka.

Fan, S., Hazell, P., Haque, T. 2000. Targeting public investments by agro-ecological zone to achieve growth and poverty alleviation goals in rural India. Food Policy, 25: 411-428.

Fan, S., Zhang, X. 2004. Infrastructure and regional economic development in rural China. China Economic Review, 15: 203-214. 
Floyd, C., Harding, A-H., Paudel, K.C., Rasali, D.P. Subedi, K., Subedi, P.P. 2003. Household adoption and the associated impact of multiple agricultural technologies in the western hills of Nepal. Agricultural Systems, 76: 715-738.

Gibson, J., Olivia, S. 2010. The effect of infrastructure access and quality on non-farm enterprise in rural Indonesia. World Development (in press).

Hanjra, M.A., Ferede, T. Gutta, D.G. 2009. Reducing poverty in Sub-Saharan Africa through investments in water and other priorities. Agricultural Water Management, 96: 10621070.

Hossain, M. 1989. Green Revolution in Bangladesh: Impact on Growth and Distribution of Income. University Press Limited, Dhaka.

Khandker, S.R., Bakht, Z., Koolwal, G.B. 2006. The poverty impacts of rural roads. World bank Policy Research Working Paper 3875. The World Bank, Washington, D.C.

Mann, R.A. 1988. New dimensions of crop productivity systems in the developing countries: Pakistan's pursuit. Agricultural Systems, 28: 213-235.

McDonald, J.F. and Moffit, R.A. 1980. The uses of Tobit analysis. Review of Economics and Statistics, 61: $318-321$.

Nkonya, E., Phillip, D., Mogues, T., Pender, J., Yahaya, M.K., Adebowale, G., Arokoyo, T., Kato, E. 2008. Impacts of pro-poor community-driven development project in Nigeria. IFPRI Discussion Paper 00756. International Food Policy Research Institute, Washington, D.C.

Rahman, 2010a. Determinants of agricultural land rental market transactions in Bangladesh. Land Use Policy, 27: 957-964.

Rahman, 2010b. Women's labour contribution to productivity and efficiency in agriculture: empirical evidence from Bangladesh. Journal of Agricultural Economics, 61: 318342. 
Rahman, S. 2009. Whether crop diversification is a desired strategy for agricultural growth in Bangladesh. Food Policy, 34: 340-349.

Rahman, S., Rahman, M. 2008. Impact of land fragmentation and resource ownership on productivity and efficiency: the case of rice producers in Bangladesh. Land Use Policy, 26: 95-103.

Rahman, O., Menken, J., Foster, A., and Gertler, P., 2001, Matlab Health and Socioeconomic Survey (MHSS), 1996, 5th ICPSR version, RAND Inter-university Consortium for Political and Social Research (ICPSR), Ann Arbour, Michigan.

Ransom, J.K., Paudyal, K., Adhikari, K. 2003. Adoption of improved maize varieties in the hills of Nepal. Agricultural Economics, 29: 299-305.

Renkow, M., Hallstrom, D.G., Karanja, D. 2001. Rural infrastructure, transaction costs and marketed surplus in Kenya. Paper presented in American Agricultural Economics Association, 2001.

Segun, F.B., Omotesho, O.A., Bello, T.A., Dayo, A.P. 2008. An economic survey of rural infrastructures and agricultural productivity profiles in Nigeria. European Journal of Social Sciences, 7: 158-171.

Shiyani, R.L., Joshi, P.K., Asokan, M., Bantilan, M.C.S. 2002. Adoption of improved chickpea varieties: KRIBHCO experience in tribal region of Gujarat, India. Agricultural Economics, 27: 33-39.

World Bank, 2010. Transport in South Asia, Bangladesh Highway http://web.worldbank.org/WBSITE/EXTERNAL/COUNTRIES/SOUTHASIAEXT/E XTSARREGTOPTRANSPORT/0,,contentMDK:20694180 pagePK:34004173 piPK :34003707 theSitePK:579598,00.html 


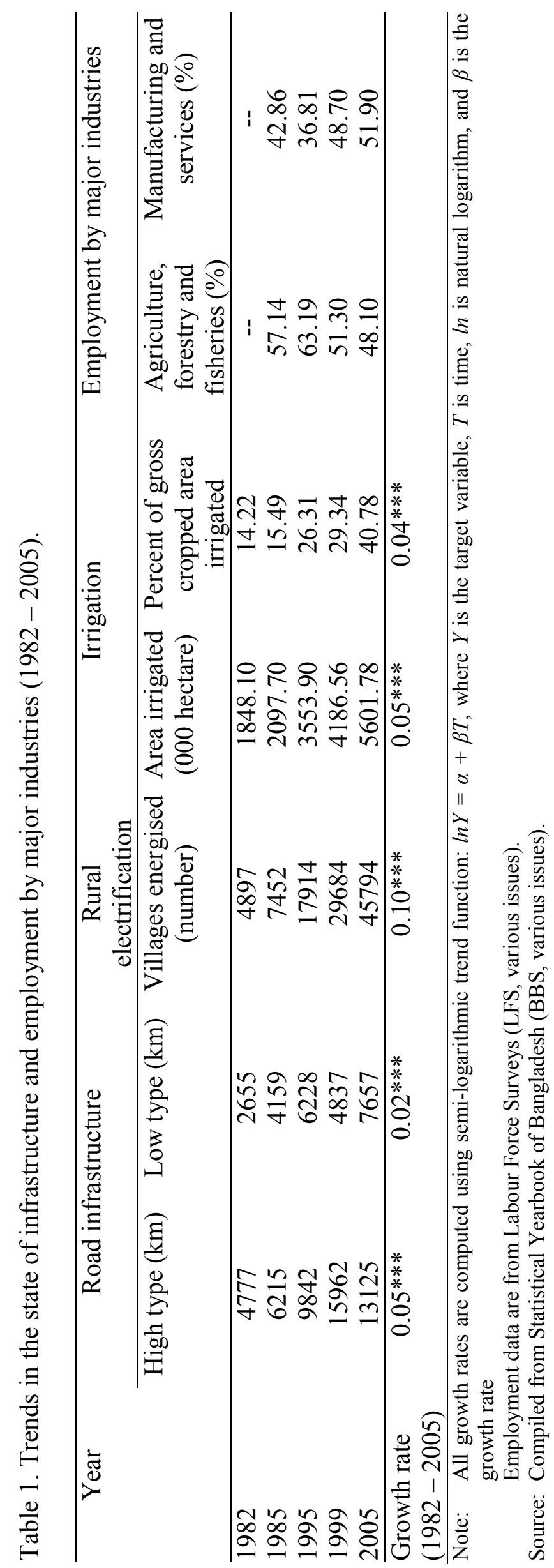




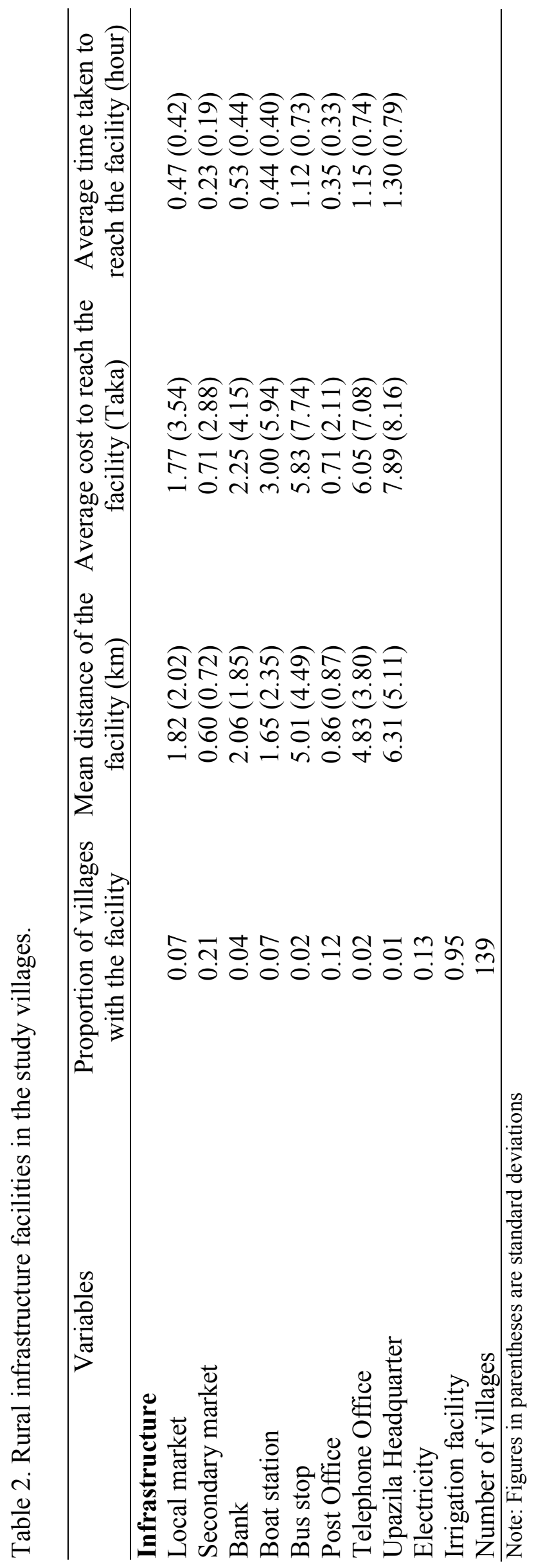




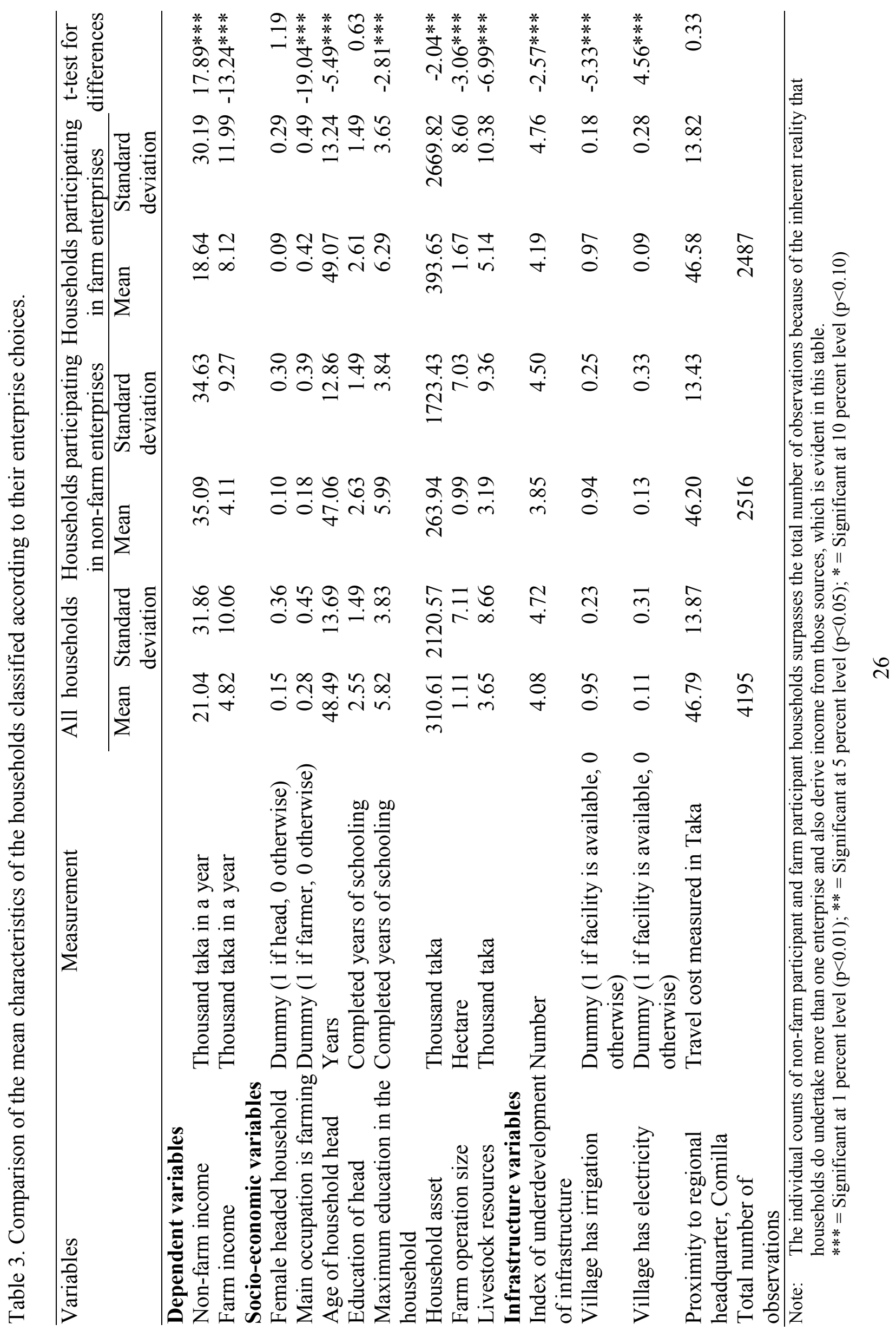




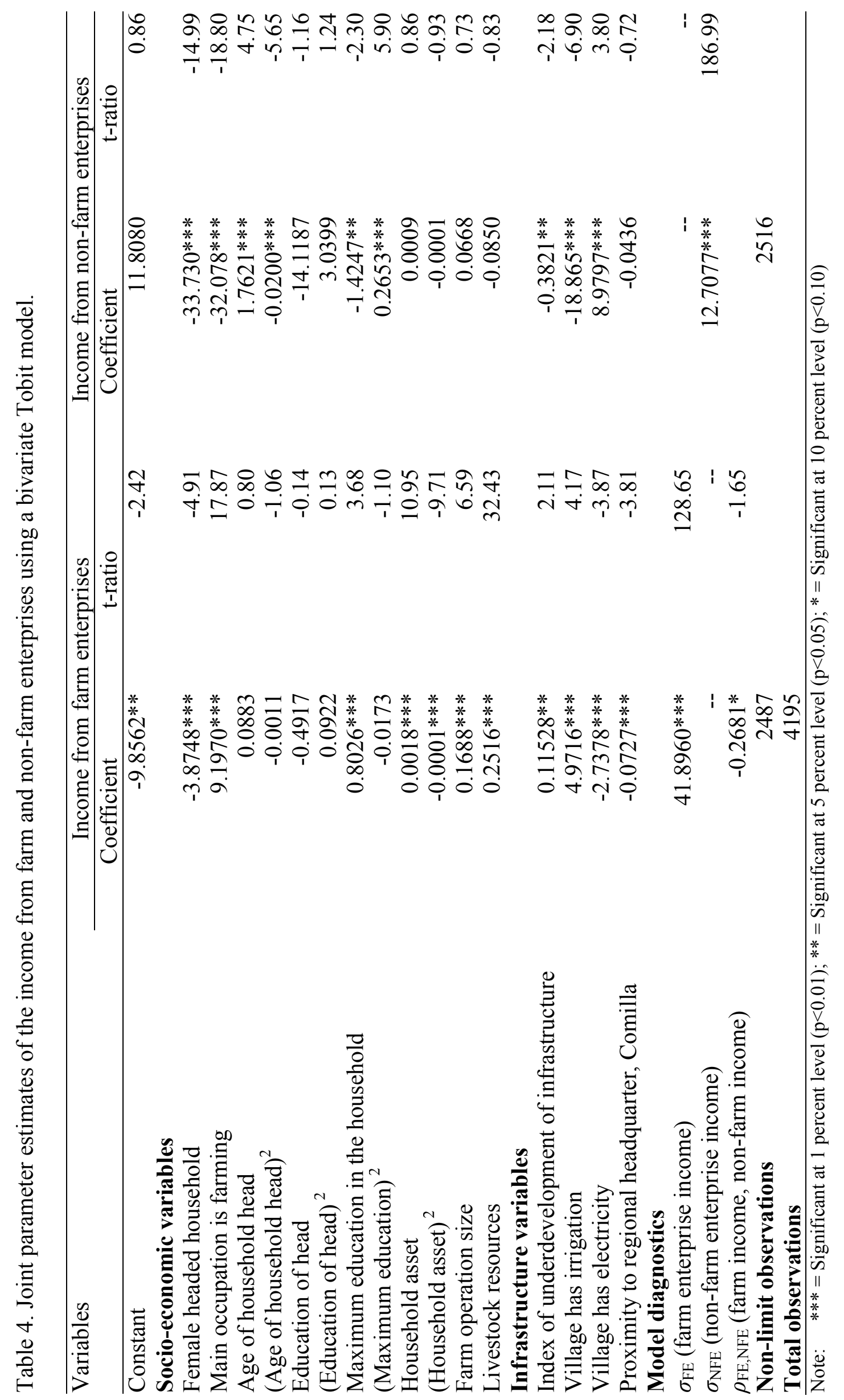




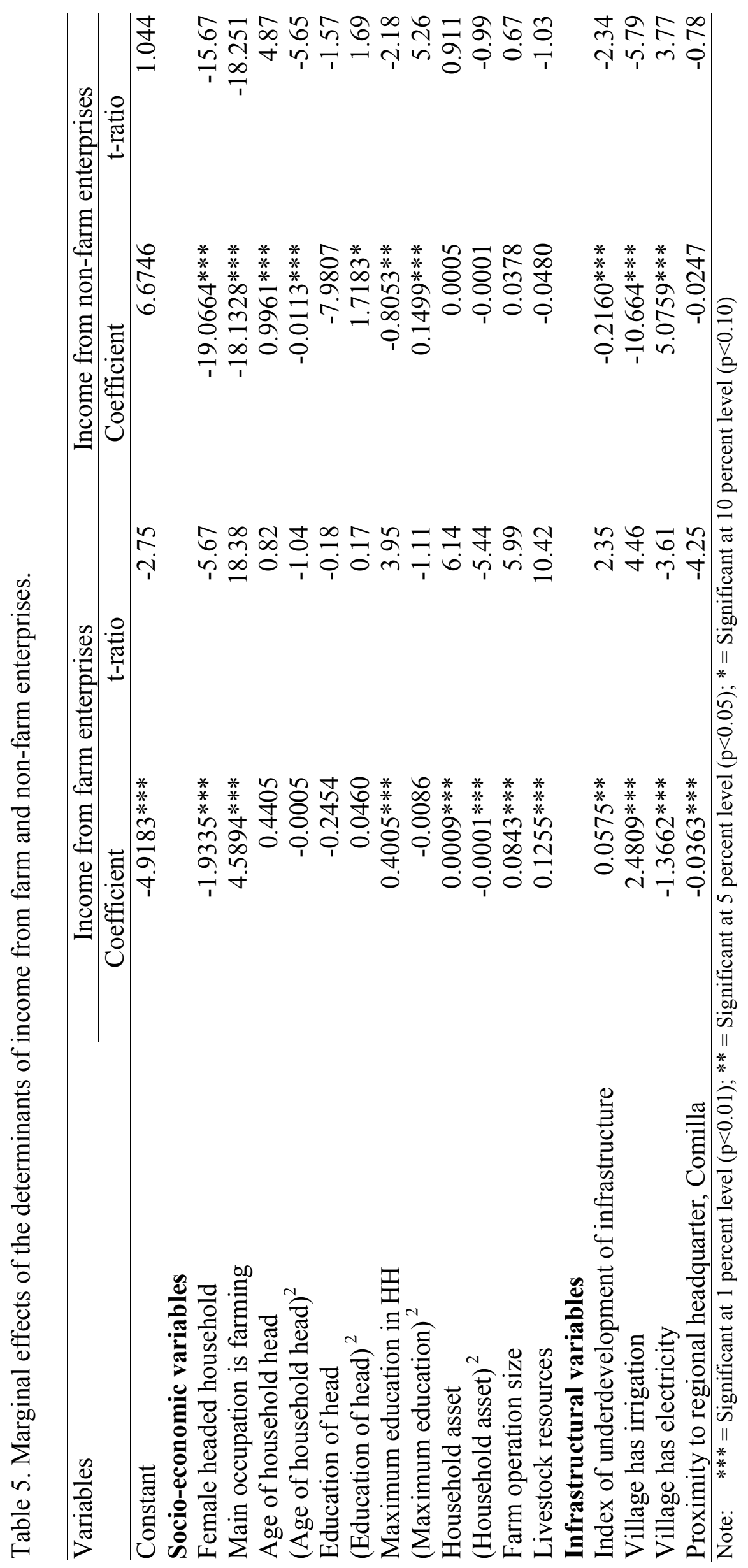

